\title{
LEARNING THROUGH THE AGES? GENERATIONAL INEQUALITIES AND INTER-GENERATIONAL DYNAMICS OF LIFELONG LEARNING
}

\author{
JOHN FIELD, University of Stirling
}

The final version of this paper was published in British Journal of Educational Studies, 61, 1, March 2013, pp. 109-19

\section{ABSTRACT}

This exploratory paper considers the concept of generation in the context of learning across the life course. Although researchers have often found considerable inequalities in participation by age, as well as strongly articulated attitudinal differences, there have so far been only a handful of studies that have explored these patterns through the perspective of generational formations. The paper is primarily conceptual, exploratory and reflective, setting out a number of approaches to the concept of generations, most of which derive largely from debates with the ghost of Karl Mannheim; it then considers how these concepts of generation have been applied to understandings of educational inequalities in recent research in Germany and the Nordic nations. It then examines the dynamics of intergenerational relations in learning, drawing on research undertaken as part of the Teaching and Learning Research Programme. The paper argues that although inter-generational dynamics are a relatively neglected dimension of Anglophone research on life chances and learning, there is a strong case for understanding their dual roles in both inequality and 
cohesion. It concludes by outlining some themes and areas for further investigation in the future.

Keywords: Lifelong learning, elder education, generations, inter-generational learning, Transitions, Lifecourse

\section{INTRODUCTION}

The nature of transitions across the life course is changing, as are the ways in which these transitions are understood and investigated by social scientists. Much earlier debate on older adults' transitions has tended to be rooted in accounts of relatively fixed social roles and age-based social stages. However, while we can detect some tendencies towards destandardisation and destandardisation of the life course in later life, we can also see significant continuities in the influences of socio-economic position, gender, and ethnicity, as well as of generational position, that continue to affect people's life chances, as well as the expectations and experiences of transition of older people.

The paper examines the interplay of these complex and contradictory structural positions and cultural locations, and consider the ways in which older people use and understand learning, formally and informally, as a way of exercising agency and recreating meaning. It will draw on recent research into the life histories of adults in Scotland, a relatively small country with a typically European pattern of demographic change. The study was concerned with agency, identity, change and learning across the life course, and this paper will concentrate on the evidence relating to experiences of transition in later life. It will 
particularly focus on the idea of 'educational generations' as a key concept that helps us understand how adults use and interpret learning in later life.

The borders, meanings and expectations of transitions across the life course are changing. So too are the ways in which these transitions are understood and investigated by social scientists. Much of this debate has focused on transitions among young people, in particular on transition from education into work. The paper will argue that reconsidering the definition and application of transition in the light of this research, and the theories that inform it, has much to offer us in understanding learning in later life. However, in the case of older adults, we also need to understand transitions and learning, as well as their meaning for people, in the context of the wider life course.

\section{TRANSITIONS AND THE LIFE COURSE}

As is common in lifelong learning, policymakers' first concern is with transitions into and through the labour market. As Commissioner Androulla Vassiliou put it in her speech on the European agenda for adult learning, lifelong learning 'is the key to a flexible, adaptable and above all employable workforce' (European Commission 2012). Social researchers have often mirrored policymakers' concern for the school-to-work transition, with rather more modest attention on training programmes for the adult unemployed or workers facing change at their workplace (eg Ryan 2001, Schoon and Silbereisen 2009). This policy focus on youth transitions first, and labour transitions second, can be understood as a response to particular critical pressures, political and economic as much as sociological and educational. However, further work is required to acknowledge the ageing society and the generally changing expectations of the different generations.

When it comes to older adults' transitions, much of the earlier debate tended to be rooted in accounts of relatively fixed social roles and age-based social stages. In education, 
these notions were codified in policy discussions of 'recurrent education'. In an influential policy discussion, the Centre for Educational Research and Innovation of the Organisation for Economic Co-operation and Development (OECD) talked of a new arrangement of the life course: moving from a sequences of stages (full-time education into work into retirement) to what it called 'alternation' between periods of work, learning and leisure through the life course (OECD 1973). Such models also influenced the ways in which many educators thought of the life course, particularly as the fame spread of the Université du troisième age movement (U3A), founded in Toulouse in 1973 (Formosa 2012). The idea of life stages as a basis for social and educational policy was popularised in Peter Laslett's book, A fresh map of life, which divided the life course into four stages: childhood, adulthood, ageing and decline (Laslett 1989).

More recent sociological approaches, inspired often by theories of reflexive individualism, have challenged notions of the life course as readily divided into fixed and sequenced stages. Influenced by the work of Ulrich Beck and Anthony Giddens among others, such approaches tend to argue that individuals and groups are increasingly required to engage in life planning in an attempt to deal with the erosion of fixed co-ordinates in their life course (Beck 1992, Giddens 1991). Empirically and conceptually, this more complex way of looking at transitions has been massively adopted and developed in recent research into youth transitions (Evans 2002, Walther and Stauber 2002). This can be seen in the debate over 'destandardisation' and 'destandardisation' of youth roles and trajectories, which draw on the sociology of risk and reflexivity to explore conditions of enduring uncertainty and liminal status positions whose outcomes are delayed and provisional (for examples, see the contributions in Furlong 2009). The sociology of ageing is increasingly engaging with some of this literature, while frequently adopting a critical stance towards stereotyping and stigmatising that will be familiar to many working in the field of adult learning, and 
emphasising the important role of community and macro-level change in understanding the significance of transitions in people's lives (Grenier 2012).

Empirically, we can also see evidence of a shift away from fixed roles and age-stages in the lives of older people (Angel and Settersten 2012). However, while we can detect some tendencies towards destandardisation and destandardisation of the life course in later life, we can also see significant continuities in the influences of socio-economic position, gender, and ethnicity, as well as of generational position, that continue to affect people's life chances, as well as the expectations and experiences of transition of older people. These in turn shape the experience of liminality, and point to continuing changes in status and role.

\section{GENERATIONS AND OLDER ADULTS' LEARNING}

How do these complex and contradictory structural positions and cultural locations impact on transitions, and how do older people use and understand learning, formally and informally, as a way of exercising agency and recreating meaning? In this section of the paper, I draw on recent research into the life histories of adults in Scotland, a relatively small country with a typically European pattern of demographic change. The study was concerned with agency, identity, change and learning across the life course, and this paper will concentrate on the evidence relating to experiences of transition in later life.

In the Learning Lives project we combined life history research with two different forms of life course research: longitudinal interpretative life-course research and quantitative survey research (for a more detailed discussion of method, see Biesta et al 2011, 113-24). This paper draws on the first two approaches, both of which used interviews conducted over a period of 36 months with the same individuals. Most interviews lasted for between 90 minutes and two hours, with each individual being interviewed several times - mostly on between three and five occasions. After each interview we wrote and then discussed short 
summaries, capturing salient experiences and early interpretations. Over time these developed into substantive records of ongoing analysis. We used two approaches for systematic dataanalysis in an iterative relationship. First, we conducted a thematic analysis focussing on larger numbers of cases around particular themes, using both theoretically driven analysis and data-driven analysis. Second, we also undertook biographical analysis focussing on the indepth analysis of individual narratives, resulting in the construction of detailed individual case studies. While we interviewed 117 people across the UK, this paper draws on the Scottish sample of 25 adults. And I must emphasise that the material cited here is presented primarily to illuminate the role of generational positions and identities in people's lives; the main aim of the people is to explore the idea of 'educational generations' as a key concept that helps us understand how adults use and interpret learning in later life, rather than to present a detailed analysis of our empirical data.

On the one hand, the notion of 'generation' refers to family positions and relationships and thus marks off phases of the life course in terms of being a child, parent, or grandparent. The notion of 'generation' also encapsulates a broader socio-economic outlook as an age-based form of social identification that is structured around people's shared experiences and understandings and the specific social and political events that have occurred throughout their lifecourse. Whereas family-based generations are subject to transition, generational cohort groups can provide lasting but perhaps less solid sources of identity. Sometimes, such markers come to represent particular sets of values and orientations, such as notions like 'the sixties generation' or 'baby boomers.'

Research into cohort based generational groupings has its roots in sociology. In what is now a classic point of reference, Karl Mannheim (1952) drew comparisons between generational bonding and class solidarity. For Mannheim, it was important to distinguish between the shared objective conditions of a cohort and their subjective consciousness of a 
shared interest based on age. In recent years a group of Finnish educational researchers has made a considerable contribution to generational analysis (see, for example, Antikainen et al 1996; Aro et al 2005; Olkinuora et al 2008), with a particular but not exclusive focus on generational differences in experiences of the education and training system in relation to such dimensions as the ways in which the education system itself has changed, the importance of external influences on education, and the ways in which the system relates with its immediate environment.

In our study, some people understood generational memberships as a way of signalling continuities between past and future. Archie Bone, a coal miner in his late 50s at the time of the interviews, connected his narrative with a broader family history when he pointed out that "five generations of our family goes back in the mining industry." When an injury had led him to retire he undertook local historical research into a mining accident. After publishing a short book on the accident, Archie then started to campaign for a memorial to the dead miners, so as to 'have something there lasting to let future generations know' (Interview 1, November 2004). Archie took education seriously as an intergenerational project, volunteering to speak in local schools about the area's history, and telling young people of his own early life as a coalminer. He, and others, spoke of generation as a form of community.

The question, then, is whether people's understandings of generational attachments lead them to adopt shared dispositions towards learning. To answer this requires us first to clarify some of the basic terminology. Most definitions of generation tend to follow Mannheim, but even so most generational categories tend to be rather broad, and their boundaries are fuzzy. As an example, let us take the definition offered by Antikainen and colleagues in their discussion of educational generations in Finland: 
A generation consists of a group of people born during the same time period and who are united by similar life experiences and a temporarily coherent cultural background. People belonging to the same generation have the same location in the historical dimension of the social process (Antikainen et al 1996, 34).

This begs some obvious questions. Precisely which 'time period', for example? And how temporary, and how coherent, is the cultural background? How can these broad generalisations be turned into categories that help us understand the meanings that people attach to generational belonging?

There is also the question, to use Mannheim's terminology, of whether we can then distinguish actual (subjectively felt) generations from potential (structurally defined) generations. While a strong relational element is highly plausible, and structural factors are certainly a necessary precondition, we also need to look for shared experiences and a degree of cultural unity as further conditions of any definition of generational groupings. Of course, any attempt at categorisation will be imprecise, as generations are not usually defined and experienced in a rigid and impermeable manner. The experience of generation will also differ, for example between the genders or classes, or between different ethnic groups. What is critical here for Mannheim is not whether generation forms an exclusive identity bond, but whether it is an important subjective and objective component of particular identities.

This is particularly significant when we come to consider learning and generation. The relationship between generation and learning has a long history in educational thinking, principally in terms of intergenerational transfers of knowledge and values so that children acquired the abilities to function in their parents' society. This 'classical' view of intergenerational socialisation as a one-way process, where the adult generations teach the young, has its roots in antiquity and survived the modernisation processes until relatively recent times. It is, though, under increasing pressure: the transfer of knowledge and skills 
from children to their parents or grandparents - has become a marked feature of the information society; among the middle aged, we may also note the transfer of values and lifestyles from adolescents to adults, as parents try to retain the lifestyle of the perpetual teenager.

\section{UNDERSTANDINGS OF GENERATION}

The place of education in the narratives illuminates the complexity of relations over time between people's learning and the rest of their lives. Almost all of the older adults told stories of discipline by strict teachers. Archie Bone, a coalminer who had gone to school in the 1930s and early 40s, wove a wider pattern into his account when he recalled the military background of his head teacher:

the local school that we went to isn't there any longer, it was knocked down a long number of years ago, and we had a headmaster that was called Captain Gracy, he had been a captain in the army, and he turned to education when he was invalided out the army and he was a very, very hard taskmaster (Interview 1, 4 November 2004).

The head inspected every child's for cleanliness and neatness, and sent errant children to wash or brush their shoes before entering the classroom.

For Archie Bone, the transition to secondary school brought another unsettling experience: he had to travel into Stirling and home again by bus, which was like going into London, you were just lost, there was masses and masses of houses and people busy running about all over the place, and we weren't used to that (Interview 1, 4 November 2004).

So school was a doubly disorienting experience, which Archie saw as tending to disembed him from his own 'tight-knit' community. And note the importance of place in the accounts 
of this older man: in a symbol of a lost world, his old school had been destroyed, while the movement from mining village into the local town was a cultural as much as a spatial shift.

Andy O'Donnell entered school in the mid-1930s, then left shortly after the War at the age of 14. Asked about his school life, his response was immediate: 'Has your education at school helped working in your job'. Answer: 'Not a bloody bit if you want the truth, not a bit' (Interview 4, 19 October 2005). As he described it, his education came more from his father than his teachers: 'he used to talk to me about Geography and History and you know current affairs so I was, he bloody educated me, I never got educated at the school 1 suppose' (Interview 1, 12 November 2004).

Corporal punishment - 'the belt' - was, for Andy, a matter of routine and nothing out of the ordinary. His career trajectory was a typical one for a working class boy of the time: apprenticeship, National Service, then a period of skilled work as a bricklayer before becoming a small employer himself. There was also a further bodily penalty, this time arising from the work that he performed: 'I went though a spot with a bad knee I knocked off a wall, and I was off my work for a long while with that, but I've still got arthritis in my knee since I got that knock, and I had to stop working with spinal arthritis because of my back, but it's a common complaint with bricklayers, bad backs' (Interview 3, 21 June 2005). He was a stalwart of his local Labour Party and an active trade unionist, and described these as the main source of his learning through adult life. While he had met academics and teachers through his work as a town councillor, he repeatedly told us that he thought them impractical: 'they hadn't a bit of common sense, I mean airy fairy stuff, not down to earth' (Interview 4, 19 October 2005). In fact, Andy made his point about 'common sense' in three of the four interviews.

Harsh discipline, which we have seen in the stories of the older adults, also featured in the memories of some interviewees who had been born in the sixties. Carmen, born in 1963 
to a lower middle class family, went to Catholic schools, and strict discipline formed part of her story. Even at primary school,

I can remember, there were a couple of teachers who were very strict, very old school, and, you know, the chalk flying, rulers flying, the belt. . (Interview 1, 20 July 2006) She lived two hundred metres away from a non-denominational school, but 'the diocese for the church dictated where you went', and she bussed to a Catholic secondary school, where some of the classes were taken by nuns. Some of the teachers also taught in a neighbouring boys' school, 'so I then had teachers who were used to teaching boys and belting them left, right and centre, and shouting and screaming a lot' (Interview 1, 20 July 2006). Another woman, Daisy Paterson, born in 1964 into a mining family, was 'always getting my knuckles slapped with the ruler, "Oh, you write properly"' (Interview 1, 3 May 2005).

Another feature of the second group was the increasing availability of higher education. Neither Archie nor Andy ever contemplated university; they didn't even consider the possibility. But for the generation born in the sixties, the availability of university places (effectively free) was a real boundary marker from the generation of their parents. While her family encouraged Carmen to pursue higher education, neither of her parents had been to university, and her mother - a secretary - in particular 'was quite bitter about her lack of opportunity, so probably quite aware that I had better opportunities' (Interview 2, 14 December 2006). Daisy Paterson completed part of her school-leaving certificate, but left half way through the final examinations to start a job as a machinist; she returned as an adult and was studying with the Open University at the time of our interviews.

We can see elements of generational specificity in these adults' accounts of their educational experiences. A simple analysis of our sample in terms of learning generations suggests a distinction between those who entered school between 1920 and 1947, and those who entered school after the Post-War reforms. For most people in the first group, education 
was a scarce resource, which ended when they could contribute to the family income by leaving school and taking work. For these older adults, school was also a place of discipline and harshness, a shocking breach with the rules that governed the previously known world of home and community. Higher education was simply not an option, and entry to the workplace came early. However, transitions into work were often disrupted by mass unemployment and the War. There were no university graduates of this age group in our sample, which is not surprising given that fewer than $2 \%$ of the population attended university at the time.

Those who entered school between 1948 and 1965 experienced a period of expansion and opportunity in secondary education, with growing access to third-level education for those who entered an apprenticeship or other form of specialist training on leaving school. In particular, the 1947 Scottish Education Act opened secondary education to girls and to the working class, and defined the minimum school-leaving age as 15; it also introduced a number of health measures for children, including free milk and vitamin supplements. Transitions into work were increasingly regulated, particularly for young men, ensuring a degree of continuing education combined with training in the early years of work. Work itself was plentiful in a tight labour market.

Of course, this group in turn can be distinguished from several younger cohorts, who entered school during a period of welfare and higher education expansion (1966-1975), or at a time of uncertain futures arising from a disrupted labour market and continued expansion of third level education and training (1975-1990). Subsequent educational generations are still in the making, though it seems patently clear that entry into the labour market during the current recession will also become an important marker.

\section{CONCLUSIONS}


What can we learn from a generational analysis of learning experience? In particular, the Finnish studies indicate that there are some important differences between generations in their attitudes towards both initial education and adult learning. Some of this is common sense: for instance, being a university student is likely to have carried a very distinctive set of meanings for young people at a time when the higher education participation rate was three per cent; the same status carries quite different meanings when the participation rate is over forty percent, and higher education entry constitutes part of the normal biography - at least for the middle classes, for girls and for some ethnic groups. But some of these studies have found much more deeply-rooted differences in orientations towards learning, resulting for example in varying generational understandings of on-the-job-training (Aro et al 2005, 466).

This brief survey of the Scottish data suggests that this approach may be worth pursuing in other contexts. As the life histories suggest, we can start to discern a number of patterns among older adults' accounts of education. For the older group, whose schooling started before the 1940s legislation had influenced the secondary system and whose youth was affected by the Scond World War, education was remembered as a largely unpleasant experience. Teaching was highly didactic; entry to work conferred access to both a recognised set of skills and a (male) adult identity; academic study, including higher education, was despised as effete ('airy fairy') and lacking in practical value. Spatial 'anchors', such as one's old school, had often been destroyed, and the institutions belonged firmly in the past. Members of this group are unlikely to respond positively to a 'lifelong learning message' and its associated procedures, particularly if they are male and from the working class.

The group who entered school in the period between 1948 and 1965 viewed university as a possible trajectory, even if it was deferred as a result of life choices, including the decision to enter the labour market. They are aware from their parents' experiences, even 
their envy, that university has not always been available as a mass option. Members of this group may prove more suited to respond positively to such lifelong learning mechanisms as the recognition of prior learning, despite their unfamiliarity with these new structures - unlike later generations, who may take credit systems and the like for granted. What is striking, though, is that certainly in the Scottish context, both groups of older adults experienced school as an arena of brutality and discipline. The difference is that the second cohort has been exposed to extended periods of liminality and understands education as a process that can continue beyond school.

This analysis, based on a generational perspective on learning, raises a number of questions about future research on learning and life chances across the life course. There is already widespread acceptance that we need a differentiated and nuanced picture of old age, a point already made by Laslett, and subsequently reinforced through the work of educational gerontologists such as Alexandra Withnall (2006) and Marvin Formosa (2012). However, while it is common to distinguish various aspects of 'difference' such as class and gender, and indeed between different levels of physical and mental (dis)ability, few have so far pursued the question of generational membership in this context. The argument outlined in this paper suggests that we should also view older adults as differentiated in terms of generational identity and location, and that this may be particularly important in the context of older people's learning.

This perspective also raises questions about longitudinal research. In recent years, longitudinal studies have made notable strides in examining patterns of participation in learning, and in particular on their economic and social outcomes, across the life course; and these studies in turn have held a particular appeal for professional educators and some policy makers (Field 2011). A generational perspective, however, prompts questions about the generalisability of findings from some types of longitudinal research, namely those based on 
cohort studies. British researchers are fortunate in being able to draw on a number of outstanding datasets drawn from the major, publicly-funded cohort studies (Bynner and Joshi 2007). And because of the relative frequency of the birth cohorts selected for study, it is also possible to conduct studies of intergenerational transmission of educational advantage (and disadvantage), as well as using inter-cohort comparisons to investigate changes in educational outcomes and social mobility over time (eg. Barnes et al 2012, Schoon 2008).

However, by definition a survey of a particular birth cohort can only encompass the experiences and outcomes of members of one single generation. This is of enormous importance in demonstrating change over the life course for members of that generation, as well as pointing to inequalities in life outcomes within that generation, but of course each generation is formed by a particular set of historical circumstances that it alone has lived through at particular phases of the life course. Even for those whose lives have been spent in the 'long peace' of post-War British society, such as members of the cohorts born in 1946, 1958 and 1970, have experienced the education system, the labour market, the family, broadcasting and the media, and the information revolution in very specific and differing circumstances. Even by comparing members of two birth cohorts does not overcome this problem entirely, as each of the two cohorts will still be shaped by its own distinctive set of shared experiences, opportunity structures and values.

While it may be possible to demonstrate that participation in adult learning had this or that particular benefit for members of a given cohort, we cannot simply assume that it will have had the same benefit for members of other cohorts, let alone that it is going to have the same benefits in the future. This is, let me say, not a criticism of cohort surveys, nor of those who use them, but rather a warning against excessive enthusiasm and over-generalisation from their findings. And it implies that from a generational perspective, other sources may become more significant in future, such as longitudinal panel surveys which repeatedly 
interview members of a household over time, and - like the cohort studies - provide data that can be analysed using advanced quantitative methods (see for example Murray 2011).

This paper has set out the case for treating generational identities and memberships as a largely neglected but important aspect of educational research. The concept merits closer attention in future, particularly in seeking to understand the place and meaning of learning in older adults' lives. It should be said, of course, that generation is unlikely to provide an allencompassing explanation of different values, behaviours and attitudes. On the contrary, my view at present is that it is less significant as a source of social identity and collective belonging than are gender, class, ethnicity and nationality, all of which powerfully shape people's experiences of generational membership. But equally, we should recognise that gender or class or ethnicity are lived and experienced differently by members of different generational cohorts. A sensitivity to generational differences is therefore potentially of value to practice and policy, as well as posing some significant opportunities for further research.

\section{REFERENCES}

Angel, J.L. and Settersten, R.A. (2012) The new realities of aging: social and economic contexts. In L. J. Waite (Ed) Perspectives on the Future of the Sociology of Aging (Washington DC, National Academies Press), 11-31. 
Antikainen, A., Houtsonen, J., Kauppila, J., and Huotelin, H. (1996) Living in a Learning Society: Life histories, identities and education (London, Routledge).

Aro, M., Rinne, R., Lahti, K. and Olkinuora, E. (2005) Education or learning on the job? generational differences of opinions in Finland, International Journal of Lifelong Education, $24(6), 459-74$.

Barnes, M., Brown, V., Parsons, S., Ross, A., Schoon, I. and Vignoles, A. (2012) Intergenerational Transmission of Worklessness: Evidence from the Millenium Cohort and the Longitudinal Study of Young People in England. Department for Education Research Report RR234 (London, Institute for Education and National Centre for Social Research).

Beck, U. (1992) Risk society: towards a new modernity (London, Sage).

Biesta, G., Field, J. Hodkinson, P., Macleod, F. and Goodson, I. (2011) Improving learning across the life course: Learning lives (Abingdon, Routledge).

Bynner, J. and Joshi, H. (2007) Building the evidence base from longitudinal data: the aims, content and achievement of the British birth cohort studies, Innovation: The European Journal of Social Science Research, 20 (2), 159-79.

European Commission (2012) One Step Up: launch conference for the European Agenda for Adult Learning. Available at http://ec.europa.eu/education/adult/conference_en.htm (accessed 20 October 2012). 
Evans, K. (2002) Taking control over their lives? Agency in young adult transitions in England and the New Germany, Journal of Youth Studies, 5 (3), 245-69.

Field, J. (2011) Researching the Benefits of Learning: the persuasive power of longitudinal studies, London Review of Education, 9 (3), 283-92.

Field, J. (2012) Biography and generation. In H. Herzberg and E. Kammler (Eds) Biographie und Gesellschaft: Überlegungen zu einer Theorie des modernen Selbst (Frankfurt-am-Main, Campus Verlag), 379-96.

Formosa, M. (2012) Education and older adults at the University of the Third Age, Educational Gerontology, 38 (1), 1-13.

Furlong, A. (Ed) (2009) Handbook of Youth and Young Adulthood: new perspectives and agendas (Abingdon, Routledge).

Giddens, A. (2001) Modernity and Self-identity: self and society in the late modern age (Cambridge, Polity).

Grenier, A. (2012) Transitions and the Life Course: Challenging the constructions of 'growing old' (Bristol: Policy Press).

Laslett, P. (1989) A fresh map of life: the emergence of the third age (London, Weidenfeld). 
Mannheim, K. (1952) Ideology and utopia. An introduction to the sociology of knowledge (London, Routledge).

Murray, S. (2011) Growing up in the 1990s: Tracks and trajectories of the 'Rising 16's': A longitudinal analysis using the British Household Panel Survey (School of Applied Social Studies, University of Stirling. Unpublished PhD Thesis).

Olkinuora, E., Rinne, R., Mäkinen, J., Järvinen, T. and Jauhaiainen, A. (2008) Promises and Risks of the Learning Society: the meanings of lifelong learning for three Finnish generations, Studies in the Education of Adults 40 (1), 40-61.

Organisation for Economic Co-operation and Development (1973) Recurrent Education: a stratregy for lifelong learning (Paris, OECD).

Ryan, P. (2001) The School-to-work Transition: a cross-national perspective, Journal of Economic Literature, 39 (1), 34-92

Schoon, I. (2008) A Transgenerational Model of Status Attainment: The potential mediating role of school motivation and education, National Institute Economic Review, 205 (1), 72-82.

Schoon, I. and Silbereisen, R. K. (Eds) (2009) Transitions from school to work:

globalization, individualization and patterns of diversity (Cambridge, Cambridge University Press) 
Walther, A. and Stauber, B. (Eds) (2002) Misleading trajectories? Integration policies for young adults in Europe? (Opladen, Leske und Budrich)

Withnall, A. (2006) Exploring influences on later life learning, International Journal of Lifelong Education, 25 (1), 29-49 